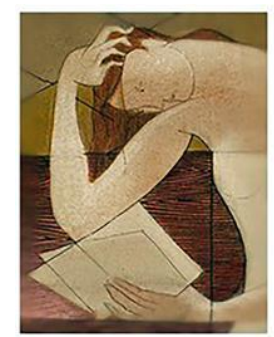

\title{
Em torno das Evocações, de Cruz e Sousa: antecedentes, circunstâncias e reações à publicação (1899) ${ }^{1}$
}

\author{
Around Evocações, by Cruz e Sousa: antecedents, circumstances of publishing and \\ early reviews
}

\begin{abstract}
Alvaro Santos Simões Junior²
Resumo: Baseia-se este artigo no levantamento de notícias, resenhas e artigos publicados na imprensa carioca, nos anos de 1890 a 1893 e de 1898 a 1899, a respeito de Cruz e Sousa e sua obra literária. Pretende-se abordar especificamente: 1) alguns dos prováveis critérios de organização de Evocações, obra póstuma trazida à luz por esforços de Nestor Vítor e outros admiradores do chamado Dante Negro, 2) as circunstâncias peculiares em que foi produzida e distribuída para o público e 3) as primeiras manifestações críticas publicadas em periódicos. Este artigo almeja também examinar a hipótese de que as mencionadas circunstâncias teriam afetado singularmente a recepção inicial desse livro simbolista.
\end{abstract}

Palavras-chave: Simbolismo; crítica literária; imprensa; Cruz e Sousa; Evocações.

Abstract: This article is based on the collection of news, reviews and articles in the Rio de Janeiro press, from 1890 to 1893 and from 1898 to 1899 , about Cruz e Sousa and his literary work. It is intended to address specifically: 1) some of the probable criteria of organization of Evocações, posthumous work brought to light by the efforts of Nestor Vítor and other admirers of the so-called Dante Negro, 2) the peculiar circumstances in which it was produced and distributed to the public and 3) the first critical manifestations regarding this work. This article also seeks to examine the hypothesis that the mentioned circumstances would have singularly affected the initial reception of this symbolist book.

Keywords: Symbolism; literary criticism; press; Cruz e Sousa; Evocações.

\section{Origens das Evocações}

Este artigo resulta do levantamento de notícias, resenhas e artigos publicados na imprensa carioca, nos anos de 1890 a 1893 e de 1898 a 1899, a respeito de Cruz e Sousa e sua obra literária. Pretende-se, nestas poucas páginas, considerar a partir da análise do vasto material: 1) alguns dos prováveis critérios de organização de Evocações, obra póstuma trazida à luz por esforços de Nestor Vítor e outros admiradores do chamado Dante Negro, 2) as circunstâncias peculiares em que o livro foi produzido e distribuído para o público; e 3) as primeiras manifestações críticas a respeito dessa obra. Este artigo almeja também examinar a hipótese de que as mencionadas circunstâncias, entre as

\footnotetext{
1 O presente trabalho foi realizado com apoio do CNPq, Conselho Nacional de Desenvolvimento Científico e Tecnológico (proc. 306284/2015-4) e da FAPESP (proc. 2017/02626-5).

2 Professor de Literatura Brasileira da Faculdade de Ciências e Letras de Assis (UNESP). Bolsista de produtividade em pesquisa do CNPq. Autor de A sátira do Parnaso (UNESP, 2007).
} 


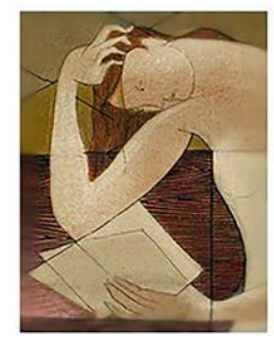

quais se destacava a morte recente do poeta, teriam afetado singularmente a recepção inicial das Evocações.

No período de 1890 a 1893, Cruz e Sousa publicou nos jornais e revistas cariocas vários poemas em prosa. A despeito das falhas e mutilações dos exemplares remanescentes, conservados na Biblioteca Nacional, constatou-se que, dos 35 textos localizados, apenas dezenove foram recolhidos à primeira edição do Missal. Além desses, apenas um foi incluído nas Evocações, obra que Cruz e Sousa pretendia publicar antes de morrer. Tratava-se de "Tenebrosa", que saiu nas Novidades do dia 24 de janeiro de 1891, distribuindo-se pela última coluna da primeira página e primeira coluna da segunda página. Posteriormente, quinze poemas em prosa abrigaram-se nas Outras evocações, livro que também poderia chamar-se Outro missal, pois muitos dos textos publicados nessa obra póstuma foram escritos juntamente com os que foram escolhidos para constar do livro publicado em 1893.

O levantamento realizado permite que dele se tirem algumas conclusões. Cruz e Sousa selecionou com muito critério os poemas em prosa que publicaria no Missal e não julgou que os textos excluídos pudessem integrar as Evocações, as quais estavam concluídas quando, poucos anos depois, veio a falecer. A exceção mencionada de "Tenebrosa" leva a pensar que os poemas em prosa das Evocações começaram a ser escritos somente após a publicação de Missal e Broquéis, o que é confirmado por necrológio publicado em $O$ País (20 mar. 1898, p. 1). Segundo Uelinton Farias Alves (2008, p. 356), o autor desse texto seria Nestor Vítor, amigo íntimo a quem Cruz e Sousa confiou seus manuscritos inéditos. Pode-se também afirmar que Cruz e Sousa exercitou-se no gênero "poema em prosa" ao mesmo tempo em que o fez o português João Barreira, cujas Gouaches vieram à luz, em Lisboa, no final de abril de 1892, altura em que pelo menos dezoito textos do Missal já estavam concluídos, conforme se comprova por suas respectivas inserções na imprensa.

A publicação das Evocações foi condicionada pela morte de Cruz e Sousa em 1898. As dolorosas circunstâncias do falecimento do poeta, rapidamente abatido pela tuberculose, encontram-se narradas com detalhes por Raimundo Magalhães Jr. (1971) e, mais recentemente, Uelinton Farias Alves (2008). Próximos ao poeta e sua família, 


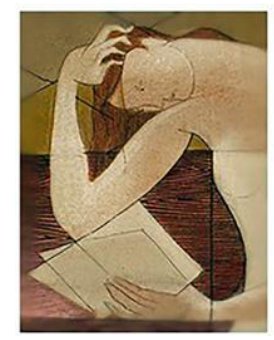

prestando toda a ajuda necessária, sempre estiveram Carlos D. Fernandes, Nestor Vítor, Saturnino Meireles, Tibúrcio de Freitas e Maurício Jubim. Coube, porém, a Nestor Vítor ficar responsável pela guarda do espólio poético de Cruz e Sousa e empenhar-se pela publicação das três obras que o chamado Dante Negro havia deixado organizadas e com os títulos definidos: Evocações, Faróis e Últimos sonetos.

Para a publicação dessas obras, que já teriam sido recusadas por editores, decidiu-se por um sistema de subscrições ou assinaturas, o qual se iniciaria com Evocações. Cada pessoa que se interessasse pela obra a ser publicada adquiriria por cinco mil-réis um cartão que seria oportunamente trocado por um exemplar. Em função de uma reclamação por atraso na entrega dos exemplares, - publicada em 7 de fevereiro de 1899 na coluna "Palestra", mantida por Artur Azevedo em O País, - soube-se que a comissão responsável pela publicação, constituída por Saturnino Meireles, Maurício Jubim, Carlos D. Fernandes e Tibúrcio de Freitas, completou com um conto e oitocentos mil-réis, retirados de seus próprios bolsos, a quantia correspondente aos custos de produção.

Em 19 de março de 1899, o jornal A Imprensa acusava o recebimento de um exemplar de Evocações, cuja produção gráfica se concluiu justamente naquele mês. Porém, como se sabe, a folha de rosto do livro trouxe a data de 1898. É provável que não tenha ocorrido atualização dos dados de imprensa para que o livro ficasse, para sempre, associado à morte de Cruz e Sousa, haja vista que era a primeira obra póstuma a vir à luz. Por essa razão, cabe tentar apreender como foi recebida a morte do poeta mediante a análise de necrológios e comentários dispersos publicados na imprensa.

\section{Necrológios, notas fúnebres e homenagens póstumas}

Com destaque gráfico, publicaram notas fúnebres os jornais $O$ País, Gazeta de Notícias e Cidade do Rio, mas o triste fato foi noticiado também, embora com mais discrição, por Jornal do Comércio e Jornal do Brasil. Para a principal folha do Rio de Janeiro, o Jornal do Comércio, os Broquéis destacavam-se entre as obras do poeta "pela sua singular e significativa originalidade” (FALECIMENTOS, 20 mar. 1898, p. 2). Já para o Jornal do Brasil Cruz e Sousa era geralmente apreciado "como escritor moderno, 


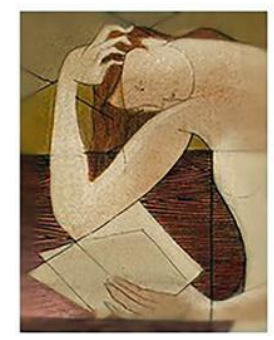

cultor extremado da forma impecável e elegante" (FALECEU, 20 mar. 1898, p. 1). A Cidade do Rio atribuiu ao poeta uma "forma coruscante, que fascinava e arrebatava, cantando, com a sua nota individual exclusiva e quente", mas pôs em discussão a cor de sua pele: "Era preto e pobre. Brancura e riqueza possuía-as, porém, no talento e no seu caráter" (CRUZ, 21 mar. 1898, p. 1). Além de vários elogios à personalidade de Cruz e Sousa e de menção à intensa repercussão de Missal e Broquéis, com a informação de que o poeta deixara inéditos três livros escritos após 1893, O País referiu-se à penúria enfrentada pelo poeta às vésperas da morte, mas acrescentando que não fora esse um episódio isolado na sofrida existência então extinta. O mais grave teriam sido as "injustiças" que lhe trouxera "a sua cor". Tantos sofrimentos sugeriram ao redator anônimo aproximá-lo do "perfil de Verlaine, cheio de sedução e compassivo" (CRUZ, 20 mar. 1898, p. 1). Como já se disse, esse texto teria sido escrito por Nestor Vítor.

Na sua "Palestra", Artur Azevedo transcreveu em 21 de março de 1898 carta que de Campos lhe enviara Azevedo Cruz, a quem a triste morte de Cruz e Sousa dera ocasião para estender-se sobre a sorte do negro no Brasil:

A monarquia legou à República cerca de cinco milhões de homens cegos, tortos, leprosos, senis, alquebrados, exaustos, analfabetos, sem honra, sem moral, inaptos para o trabalho; e é nesse esterquiliário formidável que o Crime recruta os seus agentes e a Miséria as suas vítimas.

Para Azevedo Cruz, o sofrimento de Cruz e Sousa seria prova da existência do preconceito de raça no Brasil. Artur Azevedo concordou com a afirmação e ainda acrescentou que havia, no Rio de Janeiro, ordens terceiras que não aceitavam "nas suas respectivas irmandades indivíduos que não [fossem] brancos” (A., 21 mar. 1898, p. 2).

À luz do noticiário, conclui-se que se considerava Cruz e Sousa como um poeta com a grande qualidade parnasiana, preocupação com a forma, e como uma provável vítima do difuso preconceito racial da sociedade brasileira. Assim, a publicação de suas obras póstumas poderia ser entendida, por alguns dos contemporâneos, como um desagravo à sua memória e uma espécie de justiça tardia.

Comentário de Jurema, na seção "Preto no branco" de $O$ País, transpirava uma implícita avaliação restritiva de Missal e Broquéis, pois Cruz e Sousa, segundo a visão 


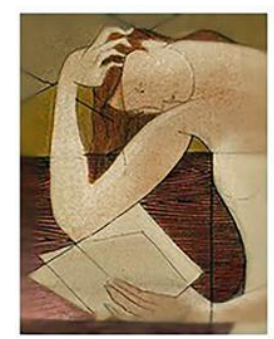

do cronista, seria "artista mal revelado ainda, mas que traíra superiores qualidades de um esteta" (JUREMA, 21 mar. 1898, p. 1, grifos nossos).

Na Gazeta de Notícias, Coelho Neto, o cronista das "Fagulhas", que assinava com a inicial N., dedicou-se integralmente a "um poeta", mas sem declinar seu nome. Fez, de início, crítica aos "governos", os quais repeliam "com asco" o homem que diante deles aparecia "extasiado, com uma lira, cantando as maravilhas do céu e da terra". Que se tratava de Cruz e Sousa se sabia, porque, segundo o cronista, o poeta em questão andava "quase maltrapilho". Alegou Coelho Neto que com ele simpatizava por ser "um simples e um forte" e "o representante da Poesia de uma raça". Como se o poeta pudesse ouvi-lo, dirigiu-se-lhe diretamente: "eras o bardo negro e não falavas com ódio relembrando o sofrimento dos teus ascendentes, falavas contente, deslumbrado porque, como se houvesses vindo do fundo agreste da Núbia, vias em tudo uma beleza e uma graça [...]”. Referiu-se também Coelho Neto ao fato de que Cruz e Sousa fora alvo do "desprezo" de seus compatriotas (N., 23 mar. 1898, p. 1). Naquela solene ocasião, não convinha ao prosador maranhense recordar que também ele votara desprezo ao falecido poeta quando este publicara o Missal. Em 1893, na sarcástica resenha de Missal que então escreveu, assinando-a com o pseudônimo de Anselmo Ribas, também não mencionou o nome do poeta e o título de sua obra deturpou para Eucharistus, em técnica comum com que a sátira torna indireto o ataque agressivo próprio do gênero (RIBAS, 5 mar. 1893, p. 1).

No rodapé da Gazeta da Tarde, em cuja redação trabalhavam amigos de Cruz e Sousa, Teófilo Barbosa dedicou palavras elogiosas a Cruz e Sousa e, no que provavelmente compreendia como uma defesa do poeta, isentou-o da "deliquescência de Verlaine e Mallarmé” e também das “jeremiadas untuosas de certos nefelibatas herbívoros" que eram vistos a "ganir à luz da lua e a fazer copioso despejo de sandices à luz do sol” (BARBOSA, 24 mar. 1898, p. 1). Prestou, assim, um desserviço à memória de Cruz e Sousa, desvinculando-o de seus muito amados mestres franceses e afastandoo dos chamados nefelibatas, portugueses em sua maioria, que comungavam com ele de um pronunciado esteticismo e, sendo como ele inconformistas, lutavam pela renovação literária, recebendo igualmente o influxo originário de Paris. 


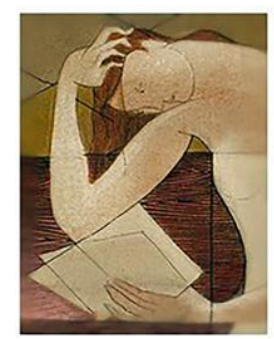

Desempenhando as funções de cronista semanal, o mais popular poeta brasileiro daquele tempo, o parnasiano Olavo Bilac, desculpou-se com seus leitores por não ter comentado a morte de Cruz e Sousa em sua crônica anterior, que já tinha sido entregue à composição quando recebeu a notícia. Se tal não houvesse ocorrido, teria sido esse, garantiu aos seus leitores, "todo o assunto da "Crônica'”. Passada apenas uma semana, coube ao poeta negro, na "Crônica" da Gazeta de Notícias, um curto fragmento final, onde se reconhecia que o finado "merecia todas as homenagens" por ter deixado ao Brasil "o belo volume dos Broquéis, - versos que, apesar dos exageros de escola a que se entregava o poeta, revelavam um talento raro, possuidor em alto grau do dom de comover e fazer sonhar". Em sutil manifestação do seu anticlericalismo, Bilac, após mencionar a realização de missa pela alma do poeta, anunciou como homenagem "mais eficaz e mais bela", a publicação do "volume póstumo" Evocações. A propósito dessa iniciativa, cumprimentou os amigos de Cruz e Sousa que dela se encarregaram (BILAC, 27 mar. 1898, p. 1). A despeito do tom cordial e respeitoso adotado, não se deve perder de vista que Bilac não deixou, nos poucos parágrafos que escreveu, de assinalar as diferenças entre sua poesia, para muitos contemporâneos perfeita, e a de Cruz e Sousa, onde se notariam "exageros de escola".

Coelho Neto, Teófilo Barbosa e Olavo Bilac representavam o gosto dominante, contra o qual se insurgira Cruz e Sousa com sua "originalidade" ou "exageros de escola”. Não se poderia esperar que partissem deles as principais e mais sinceras homenagens à memória do poeta falecido...

Cruz e Sousa ainda receberia duas homenagens significativas até que se completasse um mês de sua morte. No dia 2 de abril, a Gazeta da Tarde publicou, juntamente com os poemas "Recorda", dos inéditos Faróis, e "Ante o cadáver de Cruz e Sousa”, de Carlos D. Fernandes, desenho de Maurício Jubim representando o rosto inanimado do poeta em seu caixão (Fig. 1). 

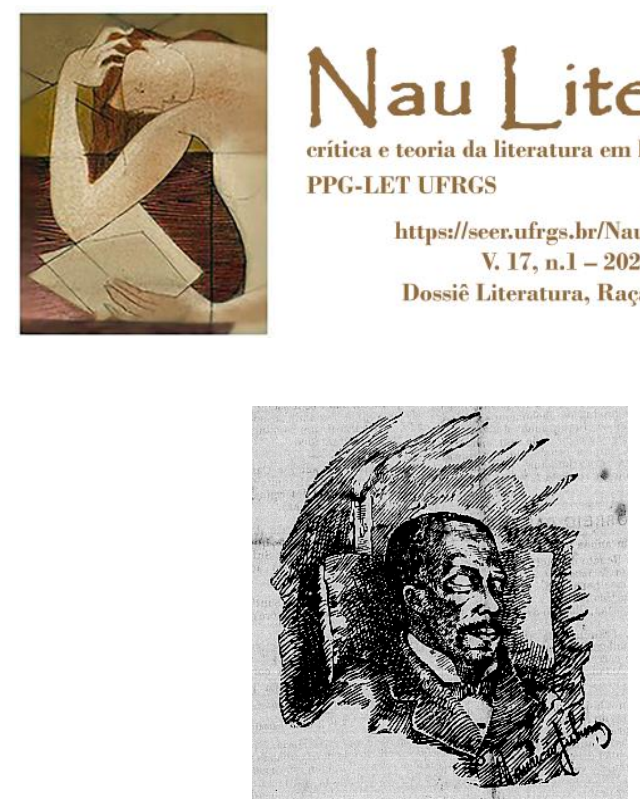

Figura 1: Cruz e Sousa por Maurício Jubim.

Fonte: Gazeta da Tarde, Rio de Janeiro, p. 1, 3.-4. col., 2 abr. 1898.

No dia 20 de abril, outra produção de Jubim (Fig. 2) ilustraria a polianteia que seria publicada na Cidade do Rio com poemas de Nestor Vítor, Ed Max, Batista Cepelos, Artur de Miranda, Orlando Teixeira e do próprio Cruz e Sousa.

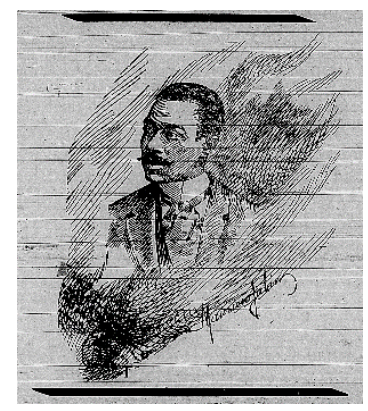

Figura 2: Portrait-charge de Cruz e Sousa por Maurício Jubim. Fonte: Cidade do Rio, Rio de Janeiro, p. 1, 3.-5. col., 20 abr. 1898.

A mencionada polianteia trazia também textos em prosa que revelavam o conceito que então se formara a respeito de Cruz e Sousa e sua obra entre os seus admiradores. Em seu texto, Carlos Dias Fernandes tratou o poeta falecido como um "estranho fenômeno", "um simbólico mistério", alheio a "todas as leis e estultas prescrições do desarrazoado saber humano" e "primeira revelação altamente intelectual" de sua raça "maldita". A sua "estranha agucidade de sentimentos" derivaria do fato de que "em sua natureza palpitava toda a sensibilidade virgem da sua raça". Entre outras informações, disse a respeito do temperamento do poeta: "Jamais alguém que não fosse puramente intelectual penetrou no templo augusto do seu afeto." Por seus amigos, sentiria "um casto e sensível ciúme". Encontrava-se também no texto um testemunho sobre o magistério estético que Cruz e Sousa exerceu: "Doutrinando verbalmente 

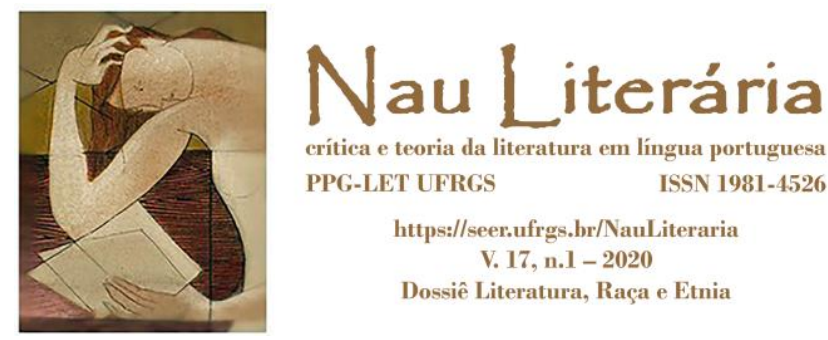

fundamentais regras de arte, ou complicadas teses estéticas, ele era tão invejavelmente grande como quando se transfigurava ante a brancura do papel ...” (FERNANDES, 20 abr. 1898, p. 1). Observe-se, nesse texto, que Fernandes enfatizava em Cruz e Sousa a condição de negro, atribuindo à sua origem africana a sua sensibilidade peculiar, e valorizava a sua postura reservada e a sua função de líder de um certo grupo de intelectuais.

No breve texto escrito por Oliveira Gomes transpareceu a acusação de que a "magoada auréola" do espírito de Cruz e Sousa não pôde "resplandecer livremente" em uma sociedade que não passava de "escuridão limosa e fria em que pulula[va]m vermes". No parágrafo anterior se fizera menção a um "sorriso burguês e ignaro que lhe sauda[ra] o coche fúnebre com uma ironia boçal e endinheirada" (GOMES, 20 abr. 1898, p. 1).

Silveira Neto, outro colaborador da polianteia, também denunciou um conflito essencial entre a sociedade brasileira de então e o poeta falecido: "Sua vida foi um tremendo contraste marcando-lhe de soluços a existência, desde o negro da sua cor e da sua miséria, pelo qual o mundo o repelia, até a sua mentalidade superior que o fazia repelir o mundo." Segundo Silveira Neto, a "vitória solene de grande Impecável da Arte numa independência brutal de fanático" teria revoltado o mundo: "um inferior em raça calcava-o, provando que a superioridade humana gira entre dois polos extremos: o Gênio e o Caráter. / O mundo vingou-se traçando no firmamento do seu Ideal o corisco da Fome" (SILVEIRA NETO, 20 abr. 1898, p. 2).

Porém, o poeta conseguira, apesar de tantos sofrimentos que lhe foram injustamente impostos, ser reconhecido pelo seu talento: “... Cruz e Sousa vestiu andrajos e descorou de miséria, mas para o mundo genuflexar-se ao seu caixão mortuário como diante o sagrado frontal de um nicho." Mais adiante acrescentou: "Limitado foi o seu amparo afetivo entre nós; exíguo foi o estímulo público ao seu talento." Para Silveira Neto, a causa do dissídio do poeta com o mundo não era exatamente a cor da pele: "Diz-se que o retiro do grande poeta do Missal era devido ao ser ele preto; engano; o mundo não faz questão de cor: exige a adaptação à mole social; e ele foi um rebelde implacável” (SILVEIRA NETO, 20 abr. 1898, p. 2). 


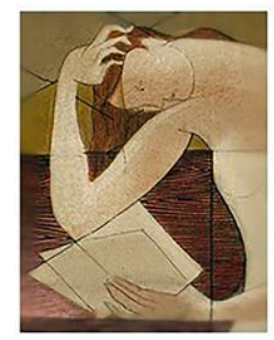

Pelos depoimentos de Oliveira Gomes e Silveira Neto, pode-se concluir que Cruz e Sousa manteve, em vida, uma postura de altivez e orgulho, pouco comum em pessoa de condição social inferior, a qual, em uma sociedade preconceituosa como se supõe ter sido a do Rio de Janeiro do final do século XIX, provavelmente criou dificuldades para a sua carreira literária, que, como se viu, não contou com o apoio dos escritores mais bem posicionados no campo literário.

\section{Uma significativa polêmica em torno das Evocações $^{3}$}

Embora a página de rosto trouxesse a data de 1898, como já se assinalou, as Evocações vieram à luz em 1899 com a qualidade de ser a primeira obra póstuma de Cruz e Sousa. A princípio, o novo livro não teve a mesma sorte das primeiras obras simbolistas do poeta, Missal e Broquéis, que, publicadas em 1893, foram alvo de bom número de textos jornalísticos. Publicadas graças a uma subscrição pública, as Evocações não puderam beneficiar-se do prestígio e do amparo de uma editora bem estruturada, o que poderia favorecer a recepção da obra. Considere-se, a propósito, o exemplo de Os simples (1892), de Guerra Junqueiro, postos à venda pela livraria Garnier e promovidos por anúncios pagos insertos na imprensa. Publicaram-se a seu respeito 26 textos (notícias, resenhas e anúncios).

A primeira resenha sobre Evocações foi escrita pelo jovem poeta Luís Guimarães Filho, que muitos anos depois (1917) se tornaria membro da Academia Brasileira de Letras. Um segundo texto saiu na coluna de crítica literária de Medeiros e Albuquerque, imortal e pioneiro reviewer do vespertino A Notícia. Por dever de ofício, o experiente jornalista não deixaria sem comentário as Evocações, mas, em grande medida, seu texto foi uma espécie de réplica a Guimarães Filho, que, por sua vez, não ficaria impassível diante das observações essencialmente sarcásticas de Medeiros e Albuquerque.

No dia 2 de abril de 1899, a Gazeta de Notícias trazia resenha de Evocações. Nela Luís Guimarães Filho expressou-se por meio de uma linguagem figurada, lançando

\footnotetext{
${ }^{3}$ Esta terceira parte coincide parcialmente, em virtude de modificações de vária natureza, com artigo publicado na revista Remate de Males (SIMÕES JR., 2009).
} 


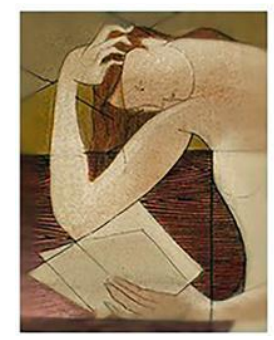

mão de metáforas e símiles, e demonstrou perceber a importância da sugestão na obra do Dante Negro:

Há neste livro páginas transparentes como uma luz pálida e fina, quase etéreas, quase imateriais, de substância impalpável. O que existe de orgânico e real na vida das palavras, chega a desaparecer, e fica-nos uma veemente sensação de pureza, de mistério, de luminoso, de imponderável, pela sugestiva força evocadora do Artista. (GUIMARÃES FILHO, 2 abr. 1899, p. 2)

Em um momento de predomínio da filosofia positivista e da crítica literária determinista, o colaborador da Gazeta de Notícias assumiu uma incomum perspectiva subjetiva, descrevendo muito mais suas impressões de leitor do que aspectos objetivos da obra em causa, como se verifica nesta passagem: “... sentimos a íntima voz do estranho prosador penetrar inefavelmente na nossa alma, como um raio de luz, como uma confidência do luar, como uma música celeste ...” (GUIMARÃES FILHO, 2 abr. 1899, p. 2).

$\mathrm{Na}$ sua resenha, Guimarães Filho também destacou o caráter espiritualizante e sublime dos poemas em prosa, reconhecendo na obra de Cruz e Sousa a tendência ao misticismo ou esoterismo:

Nas grandes asas da sua Concepção, envolta em um estilo de fluidos e maravilhas, somos arrastados da terra e da miséria, voamos aos supremos abismos onde reina a revelação, onde se tem o contato da luz, onde se conhecem os segredos do universo, por uma doce alucinação de sonâmbulo e de louco. (GUIMARÃES FILHO, 2 abr. 1899, p. 2)

Concedeu o crítico, entretanto, que, a despeito da ânsia por elevação espiritual, revelada pela maioria dos textos, havia uma força a manter o poeta preso à terra, como se notava em alguns dos poemas em prosa:

... o mesmo espírito que é aqui quase insexual, [sic] que sonha com anjos, que faz confidências ao luar, ao céu, às virgens, às auroras, e a Jesus, - é ali luxurioso e macabro, a pedir abraços estranguladores, bocas solferinas, [sic] peitos fartos e lúbricos, ventres elétricos e olhos de bacantes... (GUIMARÃES FILHO, 2 abr. 1899, p. 2)

Tão sensível para a novidade estética representada pela obra de Cruz e Sousa e mostrando-se capaz de compreendê-la em seus pressupostos estéticos e filosóficos, Guimarães Filho não conseguiu, porém, desvencilhar-se completamente das ideias hegemônicas de seu tempo, pois justificava as páginas eróticas do livro alegando que nelas: 


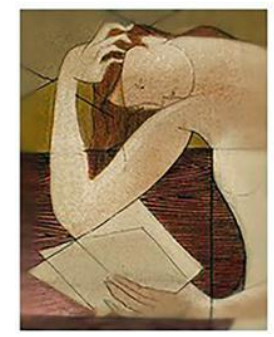

... o homem cede à fatalidade fisiológica do sangue, à morbidez lasciva da sua etnologia negra, que denuncia nele, — o sublime semi-Deus da "Mater" e da "Seráfica", — o animal sequioso de desejos insatisfeitos e formidáveis prazeres. (GUIMARÃES FILHO, 2 abr. 1899 , p. 2)

Até mesmo em aspectos da obra que pudessem ser abordados mais objetivamente, como o estilo, por exemplo, o crítico optou por considerações abstratas e expressou-se por meio de imagens, procurando à maneira de um simbolista muito mais sugerir do que descrever:

$\mathrm{Na}$ ciência do estilo, ele consegue mesmo efeitos surpreendentes: palavras que evocam resistências, e, ao lê-las, sentimos a própria sensação do contato: "carne casta e branca, tensa e veludosa"; outras lembram aromas finos, trescalam a resinas, a selvas, a bálsamos, às emanações das plantas silvestres, aos odores das corolas e à frescura dos sargaços. Aqui a prosa é alegre, chilreia como pássaros, brilha como reflexos do sol em mármores lisos; ali é uma prosa de combate, faiscando como lâminas de Toledo, cortando como serras de aço. (GUIMARÃES FILHO, 2 abr. 1899, p. 2)

Apesar da mencionada objeção baseada no racismo cientificista típico do final do século XIX, a apreciação do crítico foi, em linhas gerais, positiva. Luís Guimarães Filho valorizou inclusive, mediante a transcrição de fragmentos, uma das grandes qualidades de Cruz e Sousa, reconhecida desde a publicação de Missal e Broquéis: "Este homem de gênio consegue fazer da prosa uma música verdadeira ..." Nesse diapasão, o texto encerrou-se de maneira eloquentemente laudatória (e sugestiva):

Ah! Gênio! Gênio! Descansa na imortalidade da tua glória e espalha nos misteriosos mundos que só os mortos conhecem toda a luz da tua magnificência!

E tu, oh! noite estrelada e fria! Oh! noite bendita! Oh! noite consoladora dos poetas! segreda-lhe junto do túmulo aquelas maravilhas e aquelas confidências que ele te dizia, na música de um estilo feito de luz, tecido de neblinas, vago como um sonho de criança e etéreo como um beijo do luar... (GUIMARÃES FILHO, 2 abr. 1899, p. 2)

Em 8 de abril, J. dos Santos dedicou o seu rodapé no vespertino A Notícia, a "Crônica literária", à análise de Evocações e Cruz e Sousa, livro de Nestor Vítor. O início do texto já revelava o seu caráter de réplica a Luís Guimarães Filho:

Não é hoje tarefa muito fácil falar de Cruz e Sousa. O seu nome tornou-se para um grupo de escritores novos uma bandeira de combate. O menos que o chamam é gênio! Onde esteja, porém, a sua genialidade não sei de nenhum que o tenha dito claramente, de um modo ao alcance das inteligências simples e medíocres [sic] do rabiscador destas linhas. Quando os seus admiradores empreendem esclarecer-nos sobre a estética do Missal, dos Broquéis, ou das Evocações, começam por imitar-lhes o estilo — e não é precisamente pela limpidez que esse estilo brilha... (SANTOS, 8 abr. 1899, p. 2) 


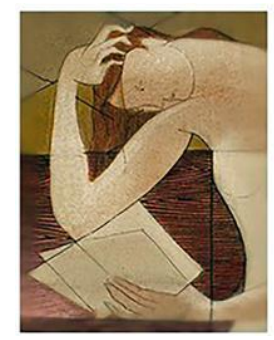

Após esse irônico nariz-de-cera, onde já se notava a rejeição à linguagem figurada empregada pelo colaborador da Gazeta de Notícas, J. dos Santos, após se atribuir, com falsa modéstia, uma inteligência simples e medíocre, começou a examinar os enunciados de Guimarães Filho procurando demonstrar que eram incompreensíveis por serem ilógicos. Incompreensível seria, inclusive, o próprio Cruz e Sousa, como confessariam seus próprios admiradores. Para J. dos Santos, tal reconhecimento não afetaria o prestígio do poeta:

Essa confissão não o amesquinha a seus olhos. Bem pelo contrário lhes parece mais uma razão para admirá-lo. É assim que escrevem da sua psicologia que ela é "estranha, incompreensível, admirável..." (SANTOS, 8 abr. 1899, p. 2, grifos do autor)

Na sequência do artigo, J. dos Santos dedicou-se a distinguir os grupos em que se dividiam os admiradores do autor de Broquéis. O primeiro grupo seria o dos admiradores sinceros que, muitas vezes, privaram da intimidade do poeta, "um nobre caráter, um bom e meigo amigo, um coração de poeta” (SANTOS, 8 abr. 1899, p. 2). Insinuou, porém, o crítico que o sentimento de amizade obscurecera o espírito crítico desse grupo:

Um impulso generoso e cheio de nobreza levou muitos a [...] exagerarem os seus elogios. Queriam - e querem ainda - como um desagravo ao seu infortúnio pessoal e imerecido, forçar a sociedade, que o maltratou, ora consciente, ora inconscientemente, a aceitá-lo como um gênio. Já que em vida ela o amesquinhou, que surja agora acima dela, elevado no mais alto dos pedestais! (SANTOS, 8 abr. 1899, p. 2)

O segundo grupo dos admiradores seria o daqueles que, "na incerteza do rumo que tomar[iam] e tendo o legítimo desejo de aparecer", cercavam os admiradores sinceros "por espírito de coterie, para, elogiando o amigo comum, serem também elogiados...” (SANTOS, 8 abr. 1899, p. 2).

O terceiro seria constituído pelos "snobs" que fingiam "sempre entender as mais ininteligíveis cousas, para parecerem espíritos de rara elevação”. Sua admiração seria, entretanto, "quase sempre desastrada: elogiam de tal modo, que os louvores parecem antes mal disfarçadas troças...” (SANTOS, 8 abr. 1899, p. 2).

Para J. dos Santos, os elogios hiperbólicos e as interpretações equivocadas da obra eram o resultado do prestígio que Cruz e Sousa construiu quando vivo ao doutrinar pelas ruas cariocas, como fazia Mallarmé privadamente em seu apartamento da Rue de 


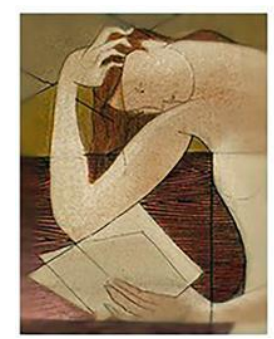

Rome, onde às terças-feiras recebia jovens poetas esperançosos. Agindo assim, o autor dos Broquéis conseguiu convencer seus inexperientes interlocutores de que detinha ideias precisas e consequentes sobre arte e literatura:

\begin{abstract}
Aquele sonhador que vivia a recrutar os amigos para em todos os cantos e a todos os propósitos lhes falar misteriosamente da Arte, do Ideal e da Poesia, palavras sempre prestigiosas, repetindo diariamente as mesmas coisas, acabava por convencê-los que ele era o representante de fórmulas novas e sublimes de tudo isso, fórmulas que ele aliás seria incapaz de definir. Com a máxima boa fé, alguns, não o compreendendo bem, capacitavam-se que o mal não era do escritor, vinha deles, que lhe ficavam muito inferiores. (SANTOS, 8 abr. 1899, p. 2)
\end{abstract}

Outros admiradores, porém, sempre segundo J. dos Santos, agiam de má fé ao declararem compreender Cruz e Sousa. Em sua opinião, haveria nisso um interesse escuso:

Se, exatamente, ele era tão cheio de sublimidades, se o penetrar o seu pensamento já era mostrar-se um espírito de élite, estranho e original! E eles, para uso do público, tomaram o partido de asseverar que nada lhes é mais luminosamente claro que os seus trechos mais obscuros. Apenas, se tentam mostrar deveras que o penetraram, são forçados ou a exprimirem-se em trechos mais obscuros ainda ou a dizerem-nos, como Nestor Vítor, que as palavras de que ele se serve têm às vezes significações opostas às do uso! Que vezes? Para se reconhecer isso exige-se por acaso uma iniciação? Uma intuição divina? (SANTOS, 8 abr. 1899, p. 2)

Nestor Vítor tinha publicado opúsculo sobre Cruz e Sousa também em 1899. Tratava-se de "monografia", escrita em 1896, que, em manuscrito, fora apreciada pelo próprio poeta dos Broquéis. Nestor Vítor aguardou concluir-se a impressão das Evocações para trazer à luz em abril de 1899 o livro de crítica que, segundo esclareceu em nota preambular, nelas se inspirou e no qual se analisaram alguns de seus textos em particular (VÍTOR, 2012, p. 21). Após reconhecer que Cruz e Sousa seria "da mais monstruosa e desapropriada expressão", se fosse "comparado com um medíocre", Nestor Vítor alegou que as "palavras enganam" e, às vezes, empresta-se "a esta ou àquela uma significação justamente oposta à que ela tem" (VÍTOR, 2012, p. 36). Nesse caso particular, fazia uma consideração de ordem geral, mas, logo adiante, disse especificamente que a adjetivação de Cruz e Sousa produzia por vezes "acepções inteiramente novas e talvez não raro diametralmente avessas à índole da palavra" (VÍTOR, 2012, p. 38). Para quem, como Medeiros e Albuquerque, havia muito criticava Cruz e Sousa pelo indiferença à significação das palavras, os trechos indiretamente 


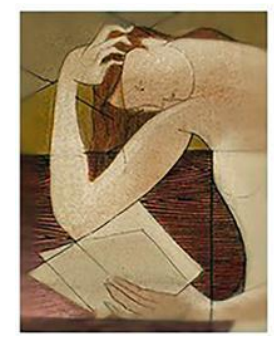

mencionados vinham a calhar, pois valiam por um reconhecimento do suposto problema por um autorizado crítico (e amigo) do poeta.

Ao final de sua resenha, J. dos Santos expressou sua opinião sobre Cruz e Sousa, que fora "um artista inacabado, imperfeito" e "incapaz, absolutamente incapaz de síntese, de sobriedade e, portanto, de propriedade de expressão". Seguindo apenas o "princípio da harmonia", o poeta seria guiado pelo ouvido, reunindo as palavras "não pelo que elas queiram dizer, mas, sobretudo, pelo que elas soam". Desse "acaso de aliteração e consonância", surgiriam ocasionalmente pensamentos "de certa originalidade, contra a vontade ou ao menos sem a mínima intenção do autor..." (SANTOS, 8 abr. 1899, p. 2). Entretanto, acabariam por predominar em seus textos "absurdos de significação", conforme sugeriu o crítico:

No turbilhão das palavras, no embalo da harmonia, julga-se às vezes que se está compreendendo: passam termos raros, exóticos, que por si sós evocam nobres ideias... Quando, porém, a gente os quer concatenar, sente que tudo se escapa. Resta apenas uma música de sílabas... O prosador das Evocações tem nelas as mesmas qualidades e sobretudo os mesmos defeitos do poeta dos Broquéis. Nestes, porém, a limitação do metro, a concisão forçada das 14 linhas do soneto obrigavam-no a ser menos difuso. Nas Evocações os períodos se alongam, se eternizam... (SANTOS, 8 abr. 1899, p. 2)

$\mathrm{O}$ artigo encerrou-se com o irônico reconhecimento de que as Evocações, "livro bizarro, extravagante," - seriam um documento de valor pelo fato de que estaria seu autor "tendo por alguns momentos a admiração de um grupo de moços, alguns deles muito mais talentosos do que ele" (SANTOS, 8 abr. 1899, p. 2). No ano seguinte, J. dos Santos voltaria ao assunto observando, também na sua "Crônica literária", que "panegiristas fervorosos da arte de Cruz e Sousa", ${ }_{4}$ quando sentiam "emoções fortíssimas" e tentavam "traduzi-las no verso", produziam versos "claros, espontâneos, harmoniosos, sem nada de comum com a arte bizarra, obscura e extravagante dos que enchem as páginas dos Broquéis" (SANTOS, 14 mar. 1900, p. 2).

Sentindo-se diretamente atingido pelo que chamou de "palmatória de padremestre" de J. dos Santos, Luiz Guimarães Filho "mordeu a isca", procurando inicialmente demonstrar que um de seus períodos, escrito em linguagem figurada,

\footnotetext{
${ }^{4} \mathrm{O}$ crítico mencionou nominalmente Frota Pessoa, Carlos Dias Fernandes e Nestor Vítor.
} 


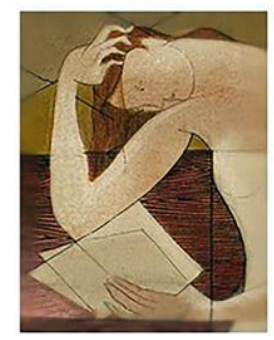

poderia ser traduzido em palavras mais precisas, mas acabou por lançar mão de um argumento de autoridade:

O Sr. J. dos Santos surpreendeu-se por eu ter escrito que a prosa das Evocações entranos na alma sem nos impressionar os sentidos. A isto responde afirmando que pelo menos os ouvidos são impressionados!

Beethoven dizia que a música era, para ele, a arte que o punha mais diretamente em contato com o mundo ideal, e que amava essa arte acima de qualquer outra por ela the penetrar no coração sem lhe impressionar os sentidos. Faz pena que o Sr. J. dos Santos não tivesse sido contemporâneo de Beethoven. (GUIMARÃES FILHO, 13 abr. 1899, p. 2 , grifos do autor)

Em uma espécie de contra-ataque, Guimarães Filho também insinuou que J. dos Santos, por não possuir a sensibilidade e os instrumentos críticos necessários para compreender Cruz e Sousa e por certa prevenção pessoal contra o poeta, fez um julgamento leviano:

... nestas breves e rápidas linhas, veja o Sr. Santos unicamente o interesse que eu tenho em lhe mostrar como S. Ex. exagerou o pecado. S. Ex., que aliás não simpatiza com Cruz e Sousa, viu tudo por óculos de aumento, e apesar disso continuou a ser míope.

Eu não discuto se o Sr. J. dos Santos gosta ou não gosta do livro de Cruz e Sousa, fato que me é totalmente indiferente. Apenas lhe quero fazer sentir que S. Ex., levando minhas palavras para o âmbito cerrado de uma análise científica, perdeu uma ótima ocasião de ficar calado. (GUIMARÃES FILHO, 13 abr. 1899, p. 2)

Essa breve polêmica, ocasionada pela publicação das Evocações e encerrada com a tréplica de Guimarães Filho, propicia um vislumbre dos conflitos em curso no campo literário brasileiro no final do século XIX, quando os simbolistas, discípulos e admiradores de Cruz e Sousa, procuravam cultivar a memória e promover a obra de seu Dante Negro como forma de afirmação grupal e de conquista de prestígio intelectual. A partir de 1898, as edições de obras póstumas e as homenagens a Cruz e Sousa significariam uma espécie de desagravo ou reparação tardia a quem tanto sofrera como presuntiva vítima do difuso preconceito racial da sociedade brasileira. Luís Guimarães Filho revelou-se com seus textos um dos mais destacados representantes desse agrupamento, que praticava ocasionalmente a crítica de sustentação. Da sua parte, Medeiros e Albuquerque, embora tivesse sido um dos divulgadores e cultivadores iniciais da estética decadentista-simbolista no Brasil no final da década de 1880, representou nessa polêmica o grupo de escritores consagrados, que se entrincheiravam nas redações dos jornais, nelas proferindo suas sentenças definitivas, e na Academia 


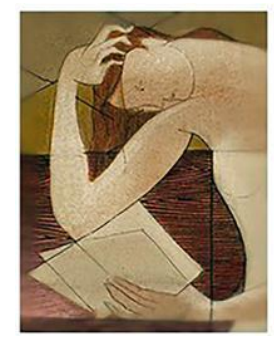

Brasileira de Letras, impedindo que a ela tivessem acesso os assim chamados nefelibatas. Ao avaliar Evocações, Medeiros e Albuquerque talvez tenha pretendido mostrar isenção e rigor excessivos para dar a entender que seu juízo crítico não se amenizara por um compreensível sentimento de comiseração despertado pelas dolorosas circunstâncias da morte do poeta do Desterro.

\section{Referências}

A., A. Palestra. O País, Rio de Janeiro, 7 fev. 1899, p. 1.

A., A. Palestra. O País, Rio de Janeiro, 21 mar. 1898, p. 2.

ALVES, Uelinton Farias. Cruz e Sousa: Dante Negro do Brasil. Rio de Janeiro: Pallas, 2008.

BARBOSA, Teófilo. À puridade. Gazeta da Tarde, Rio de Janeiro, 24 mar. 1898, p. 1.

[BILAC, Olavo.] Crônica. Gazeta de Notícias, Rio de Janeiro, 27 mar. 1898, p. 1.

CRUZ e Sousa. Cidade do Rio, Rio de Janeiro, 21 mar. 1898, p. 1.

CRUZ e Sousa. O País, Rio de Janeiro, p. 1, 20 mar. 1898.

FALECEU ontem na estação do Sítio... Jornal do Brasil, Rio de Janeiro, p. 1, 20 mar. 1898.

FALECIMENTOS. Jornal do Comércio, Rio de Janeiro, p. 2, 20 mar. 1898.

FERNANDES, Carlos D. Cruz e Sousa. Cidade do Rio, Rio de Janeiro, p. 1, 20 abr. 1898.

GOMES, Oliveira. A lágrima é ainda o nosso... Cidade do Rio, Rio de Janeiro, p. 1, 20 abr. 1898.

GUIMARÃES FILHO, Luís. Evocações. Gazeta de Notícias, Rio de Janeiro, p. 2, 13 abr. 1899.

GUIMARÃES FILHO, Luís. As 'Evocações' de Cruz e Sousa. Gazeta de Notícias, Rio de Janeiro, p. 1, 2 abr. 1899.

JUREMA. Preto no branco. O País, Rio de Janeiro, p. 1, 21 mar. 1898. 


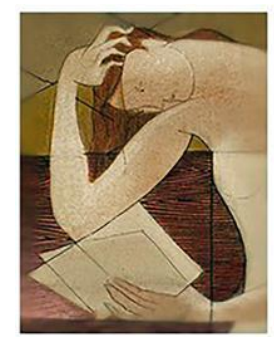

MAGAlHÃES JR., Raimundo. Poesia e vida de Cruz e Sousa. 2. ed. cor. e aum. Pref. de Paulo Rónai. São Paulo, LISA; Brasília: Instituto Nacional do Livro/MEC, 1971.

N. Fagulhas. Gazeta de Notícias, Rio de Janeiro, p. 1, 23 mar. 1898.

OS AMIGOS de Cruz e Sousa... A Imprensa, Rio de Janeiro, p. 1, 19 mar. 1899.

RIBAS, Anselmo. Inauditismo. O País, Rio de Janeiro, p. 1, 5 mar. 1893.

SANTOS, J. dos. Crônica literária. A Notícia, Rio de Janeiro, p. 2, 8 abr. 1899.

SANTOS, J. dos. Crônica literária. A Notícia, Rio de Janeiro, p. 2, 14 mar. 1900.

SILVEIRA NETO. Cruz e Sousa. Cidade do Rio, Rio de Janeiro, p. 1-2, 20 abr. 1898.

SIMÕES JR., Alvaro Santos. A repercussão nos jornais de livros simbolistas de 1899. Remate de Males, Campinas, v. 29, n. 2, p. 247-58, 2009.

SOUSA, Cruz e. Tenebrosa. Novidades, Rio de Janeiro, p. 1-2, 24 jan. 1891

VÍTOR, Nestor. Cruz e Sousa: monografia. In: SILVEIRA, Allan Valenza da. Nestor Vitor: o melhor da crítica. Ponta Grossa: Editora UEPG, 2012. p.21-48. 